\title{
PRECIPITAÇÃO EFETIVA E INTERCEPTAÇÃO PLUVIOMÉTRICA EM POVOAMENTO DE Eucalyptus spp. EM VITÓRIA DA CONQUISTA - BA
}

\author{
A. PAULA ${ }^{1}$, F. DA S. BRILHANTE ${ }^{2}$, C. TAGLIAFERRE ${ }^{3}$, M. N. DE CASTRO FILHO ${ }^{4}$, W. C. A. BATISTA, ${ }^{5}$ P.A. B. \\ BARRETO-GARCIA ${ }^{6}$ \\ Universidade Estadual do Sudoeste da Bahia \\ ORCID ID: https://orcid.org/0000-0003-3676-3846 \\ apaula@uesb.edu.br ${ }^{1}$
}

Submetido 11/04/2020 - Aceito 10/08/2020

DOI: $10.15628 /$ holos.2020.9896

\section{RESUMO}

O estudo da partição de chuva em um povoamento florestal é de suma importância, porque pequenas mudanças na frequência ou magnitude das precipitações pluviométricas têm implicações significativas para a disponibilidade de água no solo. Este estudo teve como objetivo caracterizar a precipitação efetiva, escoamento pelo tronco e interceptação da precipitação pluviométrica incidente em um povoamento de Eucalyptus spp. no município de Vitória da Conquista, BA. Os dados foram coletados no período de janeiro de 2012 a dezembro de 2013. Para quantificar os valores de cada variável foram utilizados 25 pluviômetros, dispostos a 1,5 $\mathrm{m}$ do solo e 20 coletores alocados no tronco das árvores em uma área de $400 \mathrm{~m}^{2}$ no interior do povoamento de Eucalyptus spp.. A precipitação interna anual média foi de $58,76 \%$. Precipitações mensais de até $4 \mathrm{~mm}$ tiveram as maiores interceptações, chegando a $85 \%$. O escoamento pelo tronco correspondeu a $0,06 \%$ do total precipitado. A precipitação interna, a interceptação e a precipitação efetiva, foram diretamente proporcionais a intensidade da precipitação total. A precipitação efetiva média foi de 58,82 \%. A precipitação interna, a interceptação e a precipitação efetiva, foram diretamente proporcionais a intensidade da precipitação total. A baixa precipitação total local influenciou negativamente a precipitação interna, o escoamento pelo tronco e a precipitação efetiva em relação a regiões de maior precipitação total. Em relação a interceptação, a baixa precipitação total local provocou uma maior taxa de retorno de água para a atmosfera, em comparação a regiões de maior precipitação total.

PALAVRAS-CHAVE: precipitação interna, escoamento pelo tronco, hidrologia florestal, partição de chuva.

\section{EFFECTIVE PRECIPITATION AND PLUVIOMETRIC INTERCEPTION IN PLANTATION OF Eucalyptus spp. IN VITÓRIA DA CONQUISTA - BA}

\begin{abstract}
The study of the partition of rain in a forest stand is of paramount importance, because small changes in the frequency or magnitude of rainfalls have significant implications for the availability of water in the soil. This study aimed to characterize the effective precipitation, runoff through the trunk and interception of the rainfall in an Eucalyptus spp. in the municipality of Vitória da Conquista, BA. Data were collected from January 2012 to December 2013. To quantify the values of each variable, 25 rain gauges were used, arranged at $1.5 \mathrm{~m}$ from the ground and 20 collectors allocated on the tree trunk in an area of $400 \mathrm{~m}^{2}$ in the interior of Eucalyptus spp. The average annual internal precipitation was $58.76 \%$. Monthly rainfall of up to $4 \mathrm{~mm}$ had the highest intercepts, reaching $85 \%$. Runoff through the trunk
\end{abstract}

corresponded to $0.06 \%$ of the total precipitate. The internal precipitation, the interception and the effective precipitation, were directly proportional to the intensity of the total precipitation. The average effective precipitation was $58.82 \%$. The internal precipitation, the interception and the effective precipitation, were directly proportional to the intensity of the total precipitation. Low local total precipitation negatively influenced internal precipitation, runoff through the trunk and effective precipitation in relation to regions with higher total precipitation. Regarding interception, the low local total precipitation caused a higher rate of return of water to the atmosphere, compared to regions of higher total precipitation.

KEYWORDS: internal precipitation, runoff through the trunk, forest hydrology, rain partition. 


\section{INTRODUÇÃO}

$\mathrm{Na}$ hidrologia a precipitação pluviométrica é definida como toda água proveniente do meio atmosférico, em qualquer estado físico, que atinge a superfície terrestre (TONELLO et al., 2014). A água é um dos elementos mais importantes na composição de um ambiente, pois ela interfere na fauna e na flora, tornando-se um fator vital na natureza. Segundo Calux \& Thomaz (2012) a água é responsável pelo arranjo da paisagem terrestre e estabelece a conexão entre os fenômenos da atmosfera e da litosfera, que intervém nos processos biofísicos e nas atividades humanas. Um desses fenômenos, denominado precipitação pluviométrica é a principal forma de retorno da água da atmosfera à superfície terrestre diante de processos como evaporação e condensação, estabelecendo, assim, o ciclo hidrológico.

Já a hidrologia florestal corresponde à dinâmica da água em ambientes florestais, sejam naturais ou plantados. Este balanço, segundo Li et al. (2016), é dependente das características da precipitação, como: intensidade de chuva e precipitação total; características da estrutura da copa, como índice de área foliar morfologia foliar; e parâmetros meteorológicos, como velocidade do vento, umidade relativa e radiação.

Neste contexto, é imperativo o estudo do efeito da estrutura da floresta e dos povoamentos florestais sobre a precipitação pluviométrica que efetivamente chega ao solo. À medida que se aproxima da superfície do solo, a precipitação pluviométrica pode ser interceptada por diversas barreiras, sendo a cobertura florestal a de maior importância (TONELLO et al., 2014). Isto porque parte da água que percola o dossel florestal atinge a superfície do solo com menor impacto, diminuído as perdas de solo por salpicamentos, além de aumentar o processo de infiltração, favorecendo assim a reposição de água nos lençóis freáticos.

Percebe-se, portanto, que a densidade de indivíduos arbóreos tem influência no ciclo hidrológico e no poder de penetração da água em um ecossistema florestal, da mesma forma que a morfologia e fisiologia da espécie cultivada ou ocorrente na área. Nesse sentido, vale ressaltar que a estrutura da copa é um pressuposto fundamental para determinar a capacidade de armazenamento de água no dossel, afetando diversos componentes do balanço hídrico local.

Este efeito pode ser observado por meio da interceptação das chuvas no dossel, que é considerada a primeira influência da floresta na hidrologia local. É nesse momento que ocorre o início do fracionamento da água, onde uma parte é retida temporariamente pela estrutura foliar e outra por meio da evapotranspiração, que retorna à atmosfera, mantendo o ciclo hidrológico. Denomina-se precipitação efetiva $(\mathrm{Pe})$ aquela que atinge diretamente o solo, podendo ser dividida em duas frações, a precipitação interna (Pi) e o escoamento pelo tronco (Et), que consiste nas principais fontes de reabastecimento de água no solo, podendo ter efeito significativo da vegetação em regiões áridas e semiáridas (ZHANG et al., 2015). Sendo assim, pode-se perceber que a cobertura vegetal tem estreita relação com o ciclo hidrológico, uma vez que interfere na dinâmica da água em vários compartimentos do sistema, seja nas saídas para a atmosfera ou pelo seu poder de influenciar na dinâmica da água no solo (MOURA et al., 2009). 
Em se tratando de povoamentos florestais, um debate recorrente trata do efeito da silvicultura de eucalipto sobre a precipitação pluviométrica. Esta discussão está pautada em grande parte pela importância econômica da cultura. No Brasil, os povoamentos florestais ocupavam uma área total de 7,84 milhões de hectares em 2016 , crescimento de $0,5 \%$ em relação ao ano de 2015, sendo 72,7\% do gênero Eucalyptus e 20,4\% de Pinus. Os Estados que possuem maior concentração de povoamentos florestais são: Minas Gerais, São Paulo, Paraná, Mato Grosso do Sul, Santa Catarina e Bahia (IBÁ, 2017).

Espécies do gênero Eucalyptus, geralmente apresentam um crescimento acelerado em comparação com as nativas e possuem um nível de eficiência de uso da água otimizado (ALMEIDA \& SOARES, 2003). Entender a influência das espécies arbóreas no ciclo hidrológico é fundamental para a proposição do uso racional das áreas agricultáveis, estabelecendo uma real correlação entre a silvicultura e a disponibilidade de água no solo.

A precipitação efetiva é importante para estudos dos processos de interceptação, percolação, transpiração e ciclagem de nutrientes, tanto em florestas naturais quanto em plantadas. No entanto, no Brasil ainda são poucos os trabalhos relacionados à partição da precipitação pluviométrica em diferentes coberturas vegetais. Nesse sentido, esse estudo teve como objetivo caracterizar a precipitação efetiva, escoamento pelo tronco e interceptação da precipitação pluviométrica em um povoamento de Eucalyptus spp., cultivado na Bahia, Brasil.

\section{METODOLOGIA}

O estudo foi realizado em um povoamento de Eucalyptus spp. cultivado no campus da Universidade Estadual do Sudoeste da Bahia (UESB), em Vitória da Conquista, BA, nas coordenadas $14^{\circ} 52^{\prime} 55^{\prime \prime}$ de Latitude Sul e $40^{\circ} 47^{\prime} 49^{\prime \prime}$ de Longitude Oeste. O clima, de acordo com a classificação de Köppen, é do tipo $\mathrm{CWb}$, clima tropical de altitude, com inverno seco e verão ameno. A temperatura média anual é de $25 \stackrel{\circ}{\circ}$, com precipitação média anual de $850 \mathrm{~mm}$ (BARBOSA et al., 2017). O solo é do tipo Latossolo Amarelo Distrófico Álico com relevo plano, localizado no Planalto da Conquista à $876 \mathrm{~m}$ de altitude.

O povoamento florestal foi implantado em uma área de capoeira baixa (1728 $\mathrm{m}^{2}$ ), após limpeza com trator de esteiras e preparo do solo com gradagem. O plantio ocorreu no ano 2002, adotando-se um espaçamento de $3 \mathrm{~m} \times 3 \mathrm{~m}$, com mudas seminais e adubação realizada na cova (200 gramas de Superfosfato Simples). As espécies cultivadas foram: Eucalyptus camaldulensis Dehnh., Eucalyptus robusta Sm., Eucalyptus tereticornis Sm. e Eucalyptus urophylla S.T. Blake. Os indivíduos apresentavam diâmetros à altura do peito (DAP) entre 5,0 e 24,5 cm, com média 11,54 $\mathrm{cm}$ e desvio-padrão de 4,39 cm. A altura total ficou entre 11,8 e 22,9 m, com média de 17,46 m e desvio-padrão de $3,00 \mathrm{~m}$. 


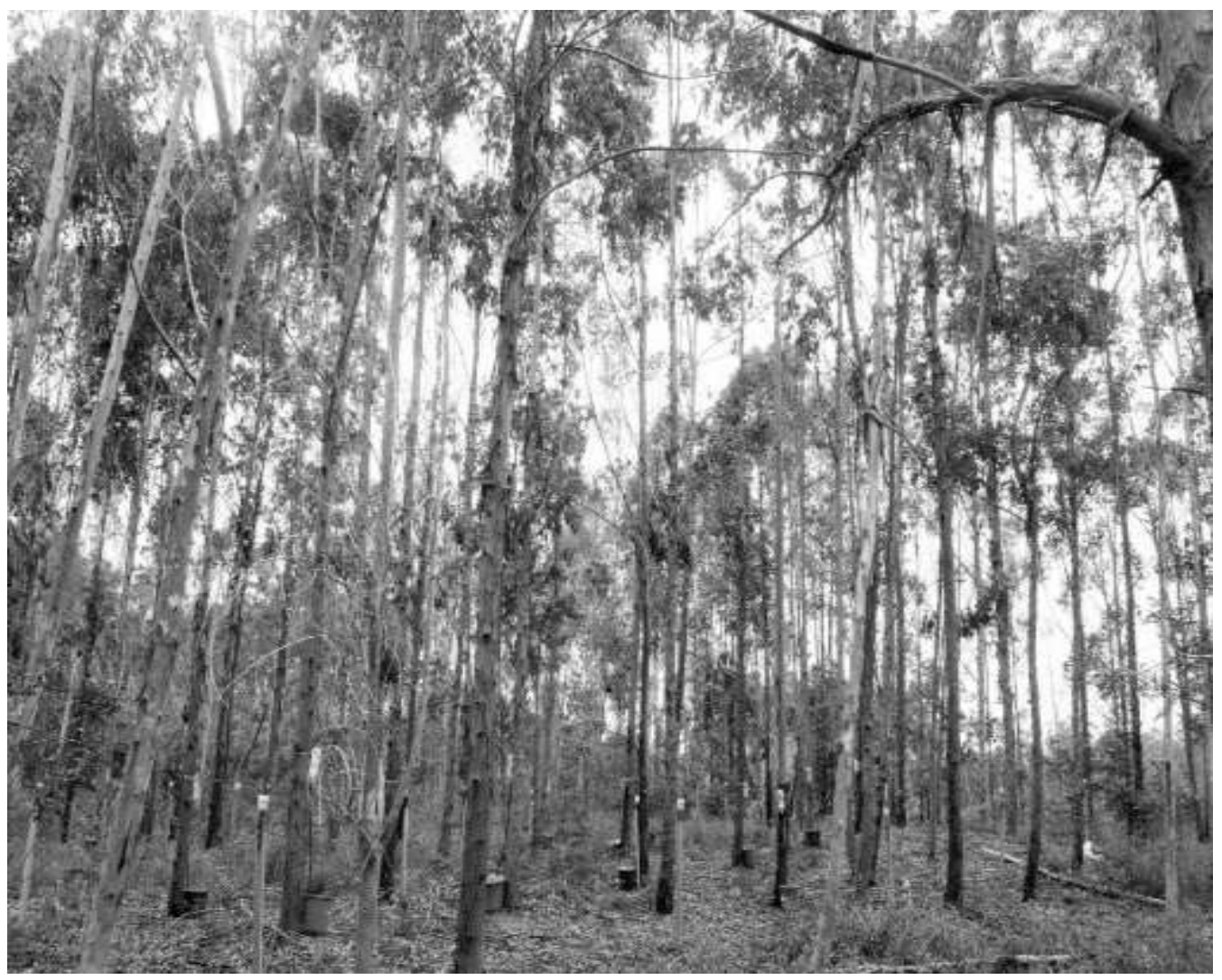

Figura 1: Povoamento de Eucalyptus spp. e coletores de precipitação interna e escoamento pelo tronco, no campus da Universidade Estadual do Sudoeste da Bahia, Vitória da Conquista, BA.

As mensurações das variáveis precipitação interna e escoamento pelo tronco foram realizadas no período compreendido entre janeiro de 2012 a dezembro de 2013. Para quantificar a precipitação interna foram instalados 25 coletores com área de captação individual de 50,24 $\mathrm{cm}^{2}$, distanciados em cinco metros entre si e altura de 1,5 metros em relação ao nível do solo. $\mathrm{Na}$ determinação da precipitação total, e, ambiente aberto, foi utilizado um pluviômetro (Ville de Paris) com área de captação de $400 \mathrm{~cm}^{2}$ a 1,5 metros acima do solo, instalado numa área sem cobertura vegetal distante a $700 \mathrm{~m}$ da parcela amostrada no povoamento de Eucalyptus spp.

$\mathrm{Na}$ avaliação do escoamento pelo tronco foram utilizados 20 indivíduos de Eucalyptus spp., tendo como parâmetros a distribuição diamétrica, disposição na parcela, tipo de casca e qualidade do fuste. Nessas árvores foram montados um sistema coletor de massa Epox para captar a água que escoou pelo do tronco (MOURA et al., 2009). Esse sistema foi ligado a uma garrafa de politereftalato de etileno (PET) que direcionava água da chuva por meio de um tubo para um recipiente com capacidade de armazenamento de 21 litros. O volume do recipiente adotado foi estimado a partir da análise de dados históricos da região, onde se estimou a máxima precipitação diária e o volume máximo do recipiente para armazenar as precipitações no local estudado.

A coleta das precipitações e do escoamento pelo tronco ocorreu diariamente, sempre nos primeiros horários do dia. Sendo assim, a precipitação efetiva foi calculada de acordo com a equação 1 (TUCCI, 2012): 
$\mathrm{Pe}=\mathrm{Pi}+\mathrm{Et}$

Em que:

$\mathrm{Pe}=$ precipitação efetiva;

$\mathrm{Pi}=$ precipitação interna; $\mathrm{e}$

Et $=$ escoamento pelo tronco.

Para o cálculo do escoamento pelo tronco utilizou-se a equação 2 (TUCCI, 2012):

$\mathrm{Et}=\frac{V}{A}$

Em que:

$\mathrm{Et}=$ escoamento pelo tronco em $\mathrm{mm}$;

$V=$ volume do coletor em L; e

$A=$ área estimada da copa em $\mathrm{m}^{2}$.

As perdas por interceptação foram obtidas pela diferença entre a precipitação total e a precipitação efetiva, de acordo com a equação 3 (TUCCl, 2012):

$\mathrm{I}=\mathrm{P}-\mathrm{Pe}$

Em que:

I = interceptação $(\mathrm{mm})$;

$\mathrm{P}=$ precipitação total $(\mathrm{mm}) ; \mathrm{e}$

$\mathrm{Pe}=$ precipitação efetiva $(\mathrm{mm})$.

Com base nos resultados foram elaborados os modelos de dispersão e de regressão, com seus respectivos coeficientes de determinação $\left(R^{2}\right)$ da precipitação interna, escoamento pelo tronco, interceptação e precipitação efetiva. 


\section{RESULTADOS E DISCUSSÃO}

Os valores de precipitação pluviométrica total variaram entre 0,00 e 292,16 mm mês $\mathrm{m}^{-1}$, devido a sazonalidade pluviométrica da região. Nos meses de março, abril e setembro de $2012 \mathrm{e}$ setembro de 2013 não foi registrada precipitação (Tabela 1). A precipitação anual média (538,24 $\mathrm{mm}$ ) foi inferior à média histórica da região, que é de 850 mm (BARBOSA et al., 2017).

Tabela 1: Valores mensais de precipitação pluviométrica total, escoamento pelo tronco, interceptação e a percentagem desses dados em relação a precipitação total em um povoamento de Eucalyptus spp., no campus da Universidade Estadual do Sudoeste da Bahia, Vitória da Conquista, BA

\begin{tabular}{c|ccccc|cccc}
\hline \multirow{2}{*}{ Mês } & \multicolumn{7}{|c|}{$(\mathrm{mm})$} & & \multicolumn{4}{c}{$\%$ em relação a P } \\
\cline { 2 - 10 } & $\mathrm{P}$ & $\mathrm{Pi}$ & $\mathrm{Et}$ & $\mathrm{Pe}$ & $\mathrm{I}$ & $\mathrm{Pi}$ & $\mathrm{Et}$ & $\mathrm{Pe}$ & $\mathrm{I}$ \\
\hline jan/12 & 14,30 & 12,35 & 0,03 & 12,38 & 1,92 & 86,36 & 0,21 & 86,57 & 13,43 \\
$\mathrm{fev} / 12$ & 28,70 & 17,60 & 0,01 & 17,61 & 11,09 & 61,32 & 0,03 & 61,36 & 38,64 \\
mar/12 & 0,00 & 0,00 & 0,00 & 0,00 & 0,00 & 0,00 & 0,00 & 0,00 & 0,00 \\
abr/12 & 0,00 & 0,00 & 0,00 & 0,00 & 0,00 & 0,00 & 0,00 & 0,00 & 0,00 \\
mai/12 & 26,90 & 10,12 & 0,03 & 10,15 & 16,75 & 37,62 & 0,11 & 37,73 & 62,27 \\
jun/12 & 21,10 & 10,05 & 0,01 & 10,06 & 11,04 & 47,63 & 0,05 & 47,68 & 52,32 \\
jul/12 & 24,70 & 17,10 & 0,07 & 17,17 & 7,53 & 69,23 & 0,28 & 69,51 & 30,49 \\
ago/12 & 48,60 & 32,98 & 0,08 & 33,06 & 15,54 & 67,86 & 0,16 & 68,02 & 31,98 \\
set/12 & 0,00 & 0,00 & 0,00 & 0,00 & 0,00 & 0,00 & 0,00 & 0,00 & 0,00 \\
out/12 & 40,40 & 29,44 & 0,02 & 29,46 & 10,94 & 72,87 & 0,05 & 72,92 & 27,08 \\
nov/12 & 292,16 & 164,69 & 0,09 & 164,78 & 127,38 & 56,37 & 0,03 & 56,40 & 43,60 \\
dez/12 & 3,20 & 0,50 & 0,00 & 0,50 & 2,70 & 15,63 & 0,00 & 15,63 & 84,38 \\
jan/13 & 115,00 & 58,57 & 0,03 & 58,60 & 56,40 & 50,93 & 0,03 & 50,96 & 49,04 \\
fev/13 & 69,40 & 36,42 & 0,02 & 36,44 & 32,96 & 52,48 & 0,03 & 52,51 & 47,49 \\
mar/13 & 4,00 & 0,60 & 0,00 & 0,60 & 3,40 & 15,00 & 0,00 & 15,00 & 85,00 \\
abr/13 & 56,00 & 34,52 & 0,01 & 34,53 & 21,47 & 61,64 & 0,02 & 61,66 & 38,34 \\
mai/13 & 8,00 & 6,50 & 0,01 & 6,51 & 1,49 & 81,25 & 0,13 & 81,38 & 18,63 \\
jun/13 & 18,00 & 11,27 & 0,00 & 11,27 & 6,73 & 62,61 & 0,00 & 62,61 & 37,39 \\
jul/13 & 22,00 & 5,42 & 0,00 & 5,42 & 16,58 & 24,64 & 0,00 & 24,64 & 75,36 \\
ago/13 & 17,80 & 14,70 & 0,00 & 14,70 & 3,10 & 82,58 & 0,00 & 82,58 & 17,42 \\
set/13 & 0,00 & 0,00 & 0,00 & 0,00 & 0,00 & 0,00 & 0,00 & 0,00 & 0,00 \\
out/13 & 22,80 & 11,80 & 0,01 & 11,81 & 10,99 & 51,75 & 0,04 & 51,80 & 48,20 \\
nov/13 & 24,60 & 18,89 & 0,02 & 18,91 & 5,69 & 76,79 & 0,08 & 76,87 & 23,13 \\
dez/13 & 218,80 & 138,99 & 0,25 & 139,24 & 79,56 & 63,52 & 0,11 & 63,64 & 36,36 \\
\hline Total & 1076,46 & 632,51 & 0,69 & 633,20 & 443,26 & 58,76 & 0,06 & 58,82 & 41,18 \\
\hline
\end{tabular}

*P = Precipitação pluviométrica total; $\mathrm{Pi}=$ Precipitação Interna; $\mathrm{Et}=$ Escoamento pelo tronco, $\mathrm{Pe}$ = Precipitação efetiva; I = interceptação.

A precipitação interna anual foi de 58,96 \% em 2012 e 58,58 \% em 2013 do total precipitado (média de 58,76 \%). Bem abaixo do encontrados em outros trabalhos realizados no Brasil, como o de Lima (1976), que em povoamento localizado no campus da Escola Superior de Agricultura "Luiz de Queiroz", no município de Piracicaba, encontrou, para Eucalyptus saligna, um 
valor de 83,6 \%. Andrade et al. (1995) em Mogi-Guaçú (SP), Balieiro et al. (2007) em Seropédica (RJ), Rodrigues e Costa (2009) em Lençóis Paulista (SP) e Sari et al. (2016) na região Sul do Brasil, todos levantamentos realizados em povoamentos de Eucalyptus grandis, encontraram precipitação interna entre $78,2 \%$ e $80,3 \%$. Vale ressaltar que estes trabalhos foram realizados em regiões de precipitações anuais muito superiores ao do presente estudo, que variam de 1250 $\mathrm{mm}$ a $1800 \mathrm{~mm}$.

A intensidade das precipitações pluviométrica total altera sensivelmente a precipitação interna, já que baixas precipitações apresentam maior índice de interceptação. Este fato pode ser observado na Tabela 1, onde as precipitações mensais até $4 \mathrm{~mm}$ tiveram as maiores interceptações, chegando a 85 \%. O presente resultado corrobora o encontrado por Facco et al. (2012) em Antônio Dias (MG). Os autores ressaltaram que as maiores interceptações ocorreram de abril a agosto, meses de baixas intensidades.

Foi observado que uma precipitação de baixa intensidade aumenta a taxa de absorção da água pela vegetação. Este fato pode ser comprovado quando comparada a precipitação interna e a precipitação total (Figura $2 \mathrm{~A}$ ).
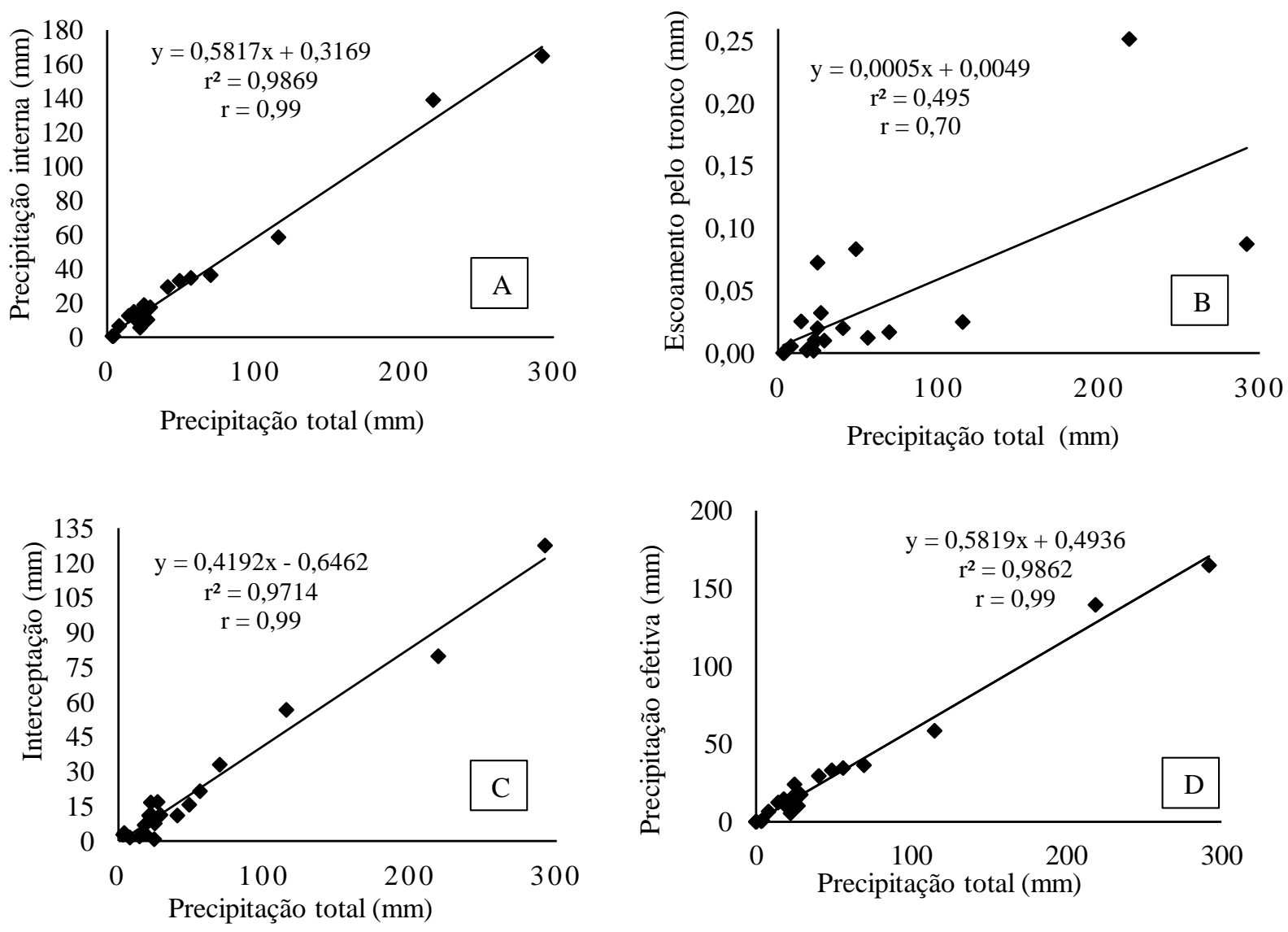

Figura 2: Valores de precipitação interna (A), escoamento pelo tronco (B), interceptação (C) e a precipitação efetiva (D) em relação à precipitação total em um povoamento de Eucalyptus spp., no campus da Universidade Estadual do Sudoeste da Bahia, Vitória da Conquista, BA

Com relação ao escoamento pelo tronco, apesar de ser desconsiderado por alguns 
autores pelo baixo percentual, ele tem importância no ciclo hidrológico. Isto ocorre devido à eficiente reposição de água ao solo, pois o escoamento pelo tronco atinge o piso florestal com velocidade baixa, muito inferior à taxa de infiltração estável, direcionando-se próximo as raízes, o que reduz o escoamento superficial (OLIVEIRA et al., 2008). Isso faz com que a infiltração ocorra de forma gradual, reduzindo as inundações e a erosão do solo. Nesse estudo, o valor do escoamento pelo tronco correspondeu a $0,06 \%$ do total precipitado, valor inferior ao encontrado por Lima (1976) que obteve 4,2\%. Também obtiveram resultados superiores Tonello et al. (2014) e Shinzato et al. (2011), com $1,0 \%$ e $0,98 \%$, respectivamente, em trabalhos realizados em povoamento de Eucalyptus cloeziana. Mais uma vez a intensidade da precipitação o maior responsável por este resultado, já que na região dos dois estudos (Iperó-SP) chove 1400 mm por ano em média.

O valor do coeficiente de determinação $\left(r^{2}\right)$ para o escoamento pelo tronco foi de 0,495 , demonstrando a pouca representação e uma baixa correlação com a precipitação total (Figura 2B). Ressalta-se que esta variável sofre influência da magnitude e intervalo de ocorrência da precipitação (SHINZATO et al.,2011) e do tipo de casca das árvores (LIMA, 1976), justificando a dispersão dos valores e o baixo valor do $r^{2}$.

$\mathrm{Na}$ Figura 2C pode-se observar maiores taxas de interceptação para menores precipitações totais. O percentual interceptado mensalmente variou de $13,43 \%$ a 85,00 \%, com uma taxa de retorno de $41,18 \%$ de água para a atmosfera (Tabela 1). Outros autores encontraram valores médios bem abaixo do presente experimento. Rodrigues \& Costa (2009), Almeida et al. (2013) e Groppo et al. (2019), entraram valores de interceptação entre 9,11 \% e 14 $\%$. Vale destacar que os trabalhos ora citados foram realizados em regiões de alta precipitação, o que reduz o percentual interceptado. Neste sentido, é importante ressaltar que a espécie, a intensidade da precipitação, dentre outros fatores, tem correlação com a perda por interceptação, dificultando ou facilitando a entrada de água no sistema. Em se tratando da capacidade de armazenamento da copa, o eucalipto apresenta um índice de área foliar tipicamente menor do que o de outras espécies florestais (LIMA, 1993).

A interceptação da chuva, na maior parte das vezes representa de 10 a $50 \%$ da precipitação total (CARLYLE-MOSES \& GASH, 2011), e tem várias funções hidrológicas e ecológicas, como por exemplo, a interceptação afeta o balanço energético (VAN DIJK et al., 2015), a disponibilidade de água para plantas e biomassa (SUTANTO et al., 2012), e a evaporação total de água no solo e recursos hídricos globais (MURRAY, 2014).

A precipitação efetiva manteve o padrão de comportamento observado para a precipitação interna e a interceptação, respondendo a diretamente à intensidade da precipitação total (Figura 2D). Precipitações de até $4,0 \mathrm{~mm}$ (Tabela 1), apresentam precipitação efetiva em torno de $15 \%$. A precipitação efetiva média foi de 58,82 \%, bem abaixo do encontrado por Tonello et al. (2014), com 86,2 \%, Andrade et al. (1995), com 86,3 \% e Lima (1976), com 87,8 \%, todos realizados em regiões de alta precipitação total. 


\section{CONCLUSÃO}

A precipitação interna, a interceptação e a precipitação efetiva, foram diretamente proporcionais a intensidade da precipitação total.

A baixa precipitação total local influenciou negativamente a precipitação interna, o escoamento pelo tronco e a precipitação efetiva, em relação a regiões de maior precipitação total.

Em relação a interceptação, a baixa precipitação total local provocou uma maior taxa de retorno de água para a atmosfera, em comparação a regiões de maior precipitação total.

\section{REFERÊNCIAS}

Almeida, A. C. D., Soares, J. V. (2003). Comparação entre uso de água em plantações de Eucalyptus grandis e Floresta Ombrófila Densa (Mata Atlântica) na costa leste do Brasil. Revista árvore, 27(2), 159-170.

Almeida, A. Q., Ribeiro, A., Leite, F. P. (2013). Modelagem do balanço hídrico em microbacia cultivada com plantio comercial de Eucalyptus grandis x urophylla no leste de Minas Gerais, Brasil. Revista Árvore, 37(3), 547-556.

Andrade, G. D. C., Da Silva, H. D., Ferreira, C. A., Bellote, A. F., Moro, L. (1995). Contribucion del agua de lluvia en la oferta de nutrientes minerales para Eucalyptus grandis. Bosque, 16(1), p. 47-51.

Balieiro, F. D. C., Franco, A. A., Fontes, R. L. F., Dias, L. E., Campello, E. F. C., Faria, S. M. D. (2007). Evaluation of the throughfall and stemflow nutrient contents in mixed and pure plantations of Acacia mangium, Pseudosamenea guachapele and Eucalyptus grandis. Revista Árvore, 31(2), 339-346.

Barbosa, V., Barreto-Garcia, P., Gama-Rodrigues, E., de Paula, A. (2017). Biomassa, carbono e nitrogênio na serapilheira acumulada de florestas plantadas e nativa. Floresta e Ambiente, $24,0-0$.

Calux, J., Thomaz, E. L. (2012). Interceptação e precipitação interna: comparação entre Floresta Ombrófila Mista e Pinus elliotttii var. elliotti. Geoambiente On-line, (19), 01-16.

Carlyle-Moses, D. E., Gash, J. H. (2011). Rainfall interception loss by forest canopies. In Forest hydrology and biogeochemistry (pp. 407-423). Springer, Dordrecht.

Facco, A. G., Ribeiro, A., Pruski, F. F., Monteiro, W. C., Leite, F. P., Andrade, R. G., Menezes, S. J. M. D. C. (2012). Técnicas de geoinformação para estimativa do balanço hídrico em eucalipto. Pesquisa Agropecuária Brasileira, 47(9), 1243-1250. 
Groppo, J. D., Salemi, L. F., Moraes, J. M., Trevisan, R., Seghesi, G. B., Martinelli, L. A. (2019). Capacidade de retenção de água do dossel vegetativo: comparação entre Mata Atlântica e plantação florestal de eucalipto. Ciência Florestal, 29(1), 96-104.

Ibá, A. (2017). Indústria brasileira de árvores. Disponível em: https://iba.org/publicacoes. Acesso dia 06 de mar. de 2019.

Li, X., Xiao, Q., Niu, J., Dymond, S., van Doorn, N. S., Yu, X., ... Li, J. (2016). Process-based rainfall interception by small trees in Northern China: The effect of rainfall traits and crown structure characteristics. Agricultural and forest meteorology, 218, 65-73.

Lima, W. D. P. (1993). Impacto ambiental do eucalipto. Editora da Universidade de São Paulo.

Lima, W. D. P. (1976). Interceptação da chuva em povoamentos de eucalipto e de pinheiro. Instituto de Pesquisas e Estudos Florestais, 13, 75-90.

Moura, A. E. S. S. D., Correa, M. M., Silva, E. R. D., Ferreira, R. L. C., Figueiredo, A. D. C., Possas, J. M. C. (2009). Interceptação das chuvas em um fragmento de floresta da Mata Atlântica na Bacia do Prata, Recife, PE. Revista Árvore, 33(3), 461-469.

Murray, S. J. (2014). Trends in 20th century global rainfall interception as simulated by a dynamic global vegetation model: implications for global water resources. Ecohydrology, 7(1), 102114.

Oliveira, L. L. D., Costa, R. F. D., Costa, A. C. L. D., Sousa, F. D. A. S. D., Braga, A. P. (2008). Modelagem da interceptação na Floresta Nacional de Caxiuanã, no leste da Amazônia. Revista Brasileira de Meteorologia, 23(3), 318-326.

Rodrigues, V. A., Costa, P. N. (2009). Precipitação efetiva e intercepção das chuvas em povoamento de eucalipto. Revista Brasileira de Engenharia de Biossistemas, 3(1), 077-86.

Sari, V., Paiva, E. M. C. D. D., Paiva, J. B. D. D. (2016). Interceptação da chuva em diferentes formações florestais na região sul do Brasil. RBRH, 21(1), 65-79.

Shinzato, E. T., Tonello, K. C., Gasparoto, E. A. G., Valente, R. O. A. Escoamento pelo tronco em diferentes povoamentos florestais na Floresta Nacional de Ipanema em Iperó, Brasil Stemflow in different forest fragments of Ipanema National Forest in Iperó, Brazil. Scientia Forestalis, 39(92), 395-402.

Sutanto, S. J., Wenninger, J., Coenders-Gerrits, A. M. J., Uhlenbrook, S. (2012). Partitioning of evaporation into transpiration, soil evaporation and interception: a comparison between isotope measurements and a HYDRUS-1D model. Hydrology Earth System Sciences, 16(8), 2605-2616.

Tonello, K. C., Gasparoto, E. A. G., Shinzato, E. T., Valente, R. D. O. A., Dias, H. C. T. (2014). Precipitação efetiva em diferentes formações florestais na Floresta Nacional de Ipanema. Revista Árvore, 38(2), 383-390.

Tucci, C. E. (2012). Hidrologia: ciência e aplicação. UFRGS Editora. 
van Dijk, A. I., Gash, J. H., van Gorsel, E., Blanken, P. D., Cescatti, A., Emmel, C., Gielen, B., Harman, I. N., Kiely, G., Merbold, L., Montagnani, L., Moors, E., Sottocornola, M., Varlagin, A., Williams, C. A., Wohlfahrt, G. (2015). Rainfall interception and the coupled surface water and energy balance. Agricultural and Forest Meteorology, 214, 402-415.

Zhang, Y. F., Wang, X. P., Hu, R., Pan, Y. X., Paradeloc, M. (2015). Rainfall partitioning into throughfall, stemflow and interception loss by two xerophytic shrubs within a rain-fed revegetated desert ecosystem, northwestern China. Journal of Hydrology, 527, 1084-1095.

\section{COMO CITAR ESTE ARTIGO:}

PAULA, A., BRILHANTE, F. da S., TAGLIAfERRE, C., CASTRO FILHO, M. N. de, BATISTA, W. C. A., BARRETOGARCIA, P.A. B. (2020). Precipitação efetiva e interceptação pluviométrica em povoamento de Eucalyptus spp. em Vitória da Conquista - BA. Holos. 36(5), 1-12.

\section{SOBRE OS AUTORES}

\section{A. PAULA}

Departamento de Engenharia Agrícola e Solos Ciências Florestais. E-mail: apaula@uesb.edu.br ORCID ID: https://orcid.org/ 0000-0003-3676-3846

\section{F. DA S. BRILHANTE}

Mestre em Ciências Florestais. E-mail: brilhante.nei@gmail.com

ORCID ID: https://orcid.org/0000-0001-9684-6761

\section{TAGLIAFERRE}

Departamento de Engenharia Agrícola e Solos Engenharia. E-mail: tagliaferre@yahoo.com.br ORCID ID: https://orcid.org/0000-0003-4776-473X

\section{N. DE CASTRO FILHO}

Doutorando em Agronomia - UESB. E-mail: manoel mrr@hotmail.com

ORCID ID: https://orcid.org/0000-0001-6783-9861

\section{W. C. A. BATISTA}

Mestre em Ciências Florestais. E-mail: willyanbatista@yahoo.com.br

ORCID ID: https://orcid.org/0000-0002-9745-0192

\section{P.A. B. BARRETO-GARCIA}

Departamento de Engenharia Agrícola e Solos Ciências Florestais. E-mail: patriciabarreto@uesb.edu.br ORCID ID: https://orcid.org/0000-0002-8559-2927

Editor(a) Responsável: Francinaide de Lima Silva Nascimento

Pareceristas Ad Hoc: Aurilene Santos e Marisa Moura De Abreu 


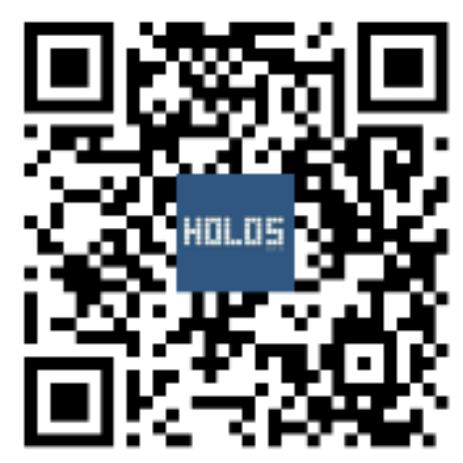

